\title{
The Meaning of Support as Narrated by Family Carers Who Care for a Senior Relative at Home
}

\author{
Peter Stoltz \\ Ania Willman \\ Giggi Udén
}

The authors' aim in this study is to illuminate the meaning of support as narrated by family members who care for a senior relative at home. This study originates from a context of advanced in-home palliative care in Sweden. Twenty individuals who cared for a senior relative at home participated. Narrative interviews resulted in a text, which the authors analyzed in three recurring phases, naive understanding, structural analyses, and comprehensive understanding, using a phenomenological hermeneutical method. They formulated two themes from the analysis: Experiencing a togetherness with others in caring and Sensing togetherness with oneself in caring. The meaning of support was understood here as Sensing togetherness. In the comprehensive understanding, the authors further illuminate this meaning using literature on the concepts of friendship, inner strength, and manageability through the sense of coherence theory. They provide suggestions for relevance to practice and further research.

Keywords: support; family carer; aged; lived experience

$\mathbf{T}$ his is an article on support for family carers who care for a senior person ( $>65$ years) at home. In this study, we examined support for family carers from a human science point of view, using family carers' narratives on their experiences from support as the point of departure. This can be seen as a more holistic and dynamic approach than what is typically presented in the scientific literature on support and thus has the potential to, for example, challenge some taken-forgranted assumptions about the rationale and nature of services to support family carers of senior persons being cared for at home (cf. Nolan, Grant, \& Keady, 2003).

The incentive to studying support for family carers in this way was twofold. First, studies of issues concerning family carers and family caregiving should be highlighted, as knowledge in this area becomes increasingly important, because the focus of health care provision for senior persons seems to be shifting away from an institutional professional care toward lay family care at home. In this focus shift, family carers are often put to the fore as health care providers in meeting the impending needs of health care for senior persons. Thus, the bulk of care for senior

AUTHORS' NOTE: The authors gratefully acknowledge that this study has been accomplished with the aid of grants from Johanniterorden i Sverige/Sweden and facilitated by Malmö University, School of Health and Society, Sweden.

QUALITATIVE HEALTH RESEARCH, Vol. 16 No. 5, May 2006 594-610

DOI: $10.1177 / 1049732305285729$

(C) 2006 Sage Publications 
persons is increasingly being shouldered by family carers (Sundström, Johansson, \& Hassing, 2002). This is a trend seen in many countries, and in Sweden there are indications of this focus shift in, for example, the form of legislation by which the state aims at facilitating for letting seniors remain in their own homes (Socialtjänstlag, 2001). In addition, staying at home can mean quality of life for seniors (cf. Borglin, Edberg, \& Rahm Hallberg, 2005). Taking the above into consideration parallel to statistical projections, which reveal a continuously aging population (SCB Statistiska centralbyrån, 2003), the need for or significance of family caring for senior persons cannot be expected to decrease dramatically in the future. Instead, support for family cares appears essential, as the responsibility for helping senior persons rests heavily on family carers (Hellström \& Rahm Hallberg, 2004).

The shifting focus of care, as argued above, was our first reason for engaging in researching support for family carers. The second reason builds on our impression from working with a systematic review on support for family carers who care for a senior person at home (Stoltz, Udén, \& Willman, 2004). Our impression of the concept of support was in accordance with but more clearly described by P. Williams, Barclay, and Schmied (2004), in that although support is a concept that is not in its infancy, it remains difficult to conceptualize, define, and measure. As regards the currently available scientific literature on support and family care, a search of the databases Medline, CINAHL, and PsychInfo reveals some 600 hits in which family carers (or lay carers, lay caregivers, next of kin, next-of-kin, relative, relatives, family) and support have been important enough to be included in the publication title (publication year later than 1997). Using the label support, researchers have reported on studies in which various interventions have been implemented that departed from a natural science point of view in their design and that were concerned with describing actions and reactions. Telephone support (Chang, Nitta, Carter, \& Markham, 2004), online support (Glueckauf, Ketterson, Loomis, \& Dages, 2004), respite care (Kristjanson et al., 2004), day care services (Dröes, Breebaart, Meiland, van Tilburg, \& Mellenbergh, 2004), and group sessions (Harding, Higginson, et al., 2004) are a few examples of recently tested approaches. Evaluations of interventions or descriptions of reactions to caregiving are recurrently done from at stresscoping point of view, whereby burden (Hirschman, Shea, Xie, \& Karlawish, 2004), anxiety (Richards, Moniz-Cook, Duggan, Carr, \& Wang, 2003), depression (Beeson, 2003; Covinsky et al., 2003), or quality-of-life (Lincoln, Walker, Dixon, \& Knights, 2004; Sands, Ferreira, Stewart, Brod, \& Yaffe, 2004) scales are used to evaluate caregiver outcomes or describe caregiving. Systematic reviews show that the evidence of effectiveness of interventions for family carers is not convincingly strong (Cooke, McNally, Mulligan, Harrison, \& Newman, 2001; Harding \& Higginson, 2003; Pusey \& Richards, 2001). Although reasons for this might be numerous, one could stem from the fact that the ontological underpinnings of the concept of support seem to remain relatively unexplored (cf. P. Williams et al., 2004). The unexplored conceptual basis can be one failing point of excellence in the search for evidence of effectiveness. A phenomenological approach to studying support for family carers might be important, as an investigation from a human science point of view might contribute to the existing body of knowledge through the debate, contrast, challenge, or development of some of the current understandings of support for family carers.

The meaning of support for family carers is not well researched. Very few researchers have explored the meaning of the lived experience of support (Gilliland 
\& Bush, 2001; Neufeld \& Harrison, 2003). We assert that notwithstanding the frequent use of the word support in family caregiving literature, what support means and how it can be achieved remain far from clear. As well, what is true about the lived experience of support might be different from what can be captured using assessment tools (cf. Nolan, Grant, et al., 1996). Bearing the above in mind, we argue that if support is to continue to be asserted as fundamental for family carers, there are incentives to study support further as a concept and principal from a human science point of view and from the context in which support is to be understood (P. Williams et al., 2004). This might result in support's being given a meaningful and fruitful substance (cf. Andersson, 1996), thus contributing to the existing body of literature on support for family carers. As a result, from what has been described so far, we undertook to interview family carers who, we believed, could tell us the meaning of support as experienced by them when caring for a senior person at home.

It might be difficult to identify potential sources of support for family carers, which is why we needed to select a context in which we believed the phenomenon of support could be illuminated by family carers' narratives. Consequently, this study was based in a research context of palliative care because of the existing Swedish advanced in-home palliative care teams (AHC) and the assumption that these teams can defensibly be identified as providers of support to family carers at home, even if the AHC is primarily for the benefit of the person dying at home (Rollison \& Carlsson, 2002). By way of how they are organized, the AHCs are able to provide a multiplicity of services that might be helpful for the family carers, for example house calls, respite care, coordination of physical aids, or sitting services. Furthermore, support for the family carer is an integral and explicit component in the World Health Organization's (WHO, 2003) definition of palliative care, on which these AHCs rest. The AHC teams provide, by definition, a physician-led, multiprofessional, qualified medical technology service that is available 24 hours a day, 7 days a week. AHC has a hospital bed standing by, has a large reception area, and primarily concerns palliative care (Beck-Friis \& Strang, 1995). AHC can replace institutional care (SBU, 1999).

\section{AIM}

Our aim in this study is to illuminate the meaning of support as narrated by family carers who care for a senior person at home.

\section{METHOD}

This study followed a phenomenological hermeneutical method inspired by the philosophy of Ricoeur (1976). The method was developed and is further developing at the University of Tromsø, Norway, and Umeå University, Sweden (Lindseth \& Norberg, 2004). This research method is essentially about illuminating the meaning of lived experiences of phenomena in humans' lifeworld. An important and natural way that humans use for communicating meaning is narratives (Mishler, 1986). Therefore, the data in this study consisted of narratives with interviewees gained 
through unstructured interviews, which were tape-recorded then transcribed verbatim into text.

The experience of a phenomenon as it is lived will always remain private, but its meaning can become public (Ricoeur, 1976). In the phenomenological hermeneutic process, the meaning can become public by way of the interpretation process. Thus, phenomenology presupposes hermeneutics, and vice versa; the transcribed text needs interpretation for the meaning of the lived experience to be illuminated (Lindseth \& Norberg, 2004; Ricoeur, 1981). In the interpretation procedure, the transcribed interview text was analyzed in three recurring phases: naive understanding, structural analyses, and comprehensive understanding. The analysis encompassed a continuous dialectical movement between the whole and the parts of the text, and, correspondingly, between understanding and explanation. The interpretation meant a following of the movement of the text from what it said to what it talked about, verified, corrected, and deepened by way of structural analyses (Ricoeur, 1976, 1991). In the initiation of the analyses, we carried out a thorough reading of each interview to capture naively a first surface conjecture of the text as a whole (Lindseth \& Norberg, 2004; Ricoeur, 1976, 1991). This was the naive reading, and it provided the direction for further structural analyses, foremost in terms of the identification of meaning units, that is, sequences of text that convey meaning. The structural analyses were thematic, and they involved an identification, condensation, and organization of meaning units. In the process of following the text from what it said to what it talked about, the structural analyses played a mediating role. They are what invites a deepened understanding of the initial impression, that is, the naive reading, but also involved a rectifying of the same. The structural analyses can rectify, reject, or confirm the impression from the naive reading. The final phase, the interpreted whole, should be regarded as the result. It is the center of gravity in the interpretation. It takes into account the naive reading, the structural analysis, and the preunderstanding of the authors. In the interpreted whole, the interview text of this study was mirrored in literature, opening up a widened and deepened understanding of the text (Lindseth \& Norberg, 2004). In our choice of literature, we sought to illuminate deeply human experiences, and therefore we have turned to theoretical and philosophical literature that can widen and deepen our understanding of lived experiences. The literature's perspective was not forced on the text; instead, we aimed to let the literature illuminate the text and let the text illuminate the literature (cf. Lindseth \& Norberg, 2004).

\section{Research Context}

The southern region of Sweden is divided into 33 municipalities. At the initiation of this study in the spring and summer of 2002, AHC was well established at three hospitals in this region, covering 12 municipalities. This study was performed in collaboration with these AHCs. We used a purposive sample, whereby family carers of senior cohabiting persons were approached in the following way: AHC nurses delivered a letter explaining the aim and procedure of the study. They then proceeded to inquire about family carers' consent to disclose their telephone number to the authors. If consent was granted, the first author (P.S.) called them and asked if they could participate. Given the sensitive family situation, we considered this way of approaching the participants the least intrusive. The letter was delivered by AHC 
team nurse, to whom the family carers did not need to justify declining to participate. Because of the in-person delivery of the letters, there was no need for any lists of names or addresses of family carers. We did not supervise the total number of letters distributed by the AHC nurses.

\section{Participants and the Interviews}

Twenty-eight family carers were in telephone contact with P.S. Of these, 3 did not want to participate, because they felt totally occupied with caregiving or did not regard themselves as caregivers. One family carer did not cohabit with her charge, 2 did not care for senior persons, and 2 family carers' charges died before the interview was conducted; consequently, these 8 were not included. In our collective experience, about 20 interviews would be appropriate for this study's methodological point of departure. Conducting several interviews should contribute to a deeper understanding of the phenomenon through rich and varied descriptions, although it can be argued that one interview might be sufficient, from a human science point of view, for describing the variations, contents, and outlines of a phenomenon, depending on the topic and scope of investigation (Malterud, 2001).

We carried out narrative interviews (cf. Mishler, 1986) with 20 family carers. All but 1 of the 20 participants chose to be interviewed in their home. Although it was not a criterion, all participants $(N=20)$ were spouses. Thirteen wives and 7 husbands participated. Family carers' ages ranged from 54 to 84 years $(M=71.2)$, and the age of the persons cared for ranged from 66 to 89 years $(M=75.8)$. All family carers and the senior persons for whom they cared were affiliated with an AHC when the interview was conducted. The AHCs were family carers' main source of support in managing caregiving at home. All senior persons were at the end of life, dying from an incurable cancer. Families participating in this study had been affiliated to an AHC for 3 weeks to 24 months ( $M=5.3$ months). The interviews lasted between 30 and 80 minutes ( $M=50$ minutes). Transcripts amounted to 1,143 double-spaced pages.

The first author (P.S.) performed all interviews between September 2002 and December 2003. Participants were asked to narrate about their experiences of support using the opening question, Please tell me about your experiences of support. The participants narrated with a minimum of interruptions. Open-ended follow-up questions were used to encourage narration-for example, "Can you tell me more?" "Can you give me an example?" "How did you feel?" and" What were your thoughts?" In the follow-up questions, we also aspired to keep the focus on the support the family carers received rather than on the support their charge received. The participants were also asked to narrate about negative experiences concerning support, that is, to illuminate the phenomenon of support in its absence: "Please tell me about a time when you felt that the support wasn't so good." All interviews were then transcribed verbatim, including pauses, weeping, laughter, and so on (P.S.).

\section{Ethical Approval}

We obtained informed consent to being interviewed from all participants. None of the authors was affiliated with any AHC. The study was approved by the research ethics committee at Lund University, Sweden (LU 233-02). 


\section{INTERPRETATION AND FINDINGS}

Although P.S. was in the forefront as regards the interpretation procedure, all authors participated throughout the analysis. The result of the interpretation follows below. To increase comprehensibility, the structural analyses will be preceded by a brief description of procedure (cf. Strandberg, Norberg, \& Jansson, 2000).

\section{Naive Understanding}

In the family carers' narratives, the meaning of support as resting assured in the resourcefulness of others was particularly strong. This could be exemplified in situations in which the family carers felt confident that others would make sure that things turned out well, knowing that they would be helped to help their loved one. This meaning was also elucidated in corresponding but subversive situations when family carers instead felt abandoned and disappointed, feeling let down in a sense that nobody recognized their needs. In such cases, family carers spoke of feeling alone, that their suffering or that of the person they care for was taken lightly or not acknowledged. The meaning of support was also to be sensing a genuineness in others, that people, through their way of being, speaking, and doing things showed that they really cared for the family carer and their loved one equally.

Support means resting assured with a resourcefulness within oneself. This could be exemplified when family carers narrated about being a uniquely resourceful person, for instance, in their sense of being calm and confident in knowing what to do and where to turn for warranted help. Family carers spoke of being surprised at their own resourcefulness in difficult and trying situations. Support means drawing on the connection with oneself, encapsulated in a sense of being strong or stubborn, or finding some time to oneself.

\section{Structural Analyses}

We read the text thoroughly and identified narratives about support. The narrative categories were then lifted out of the text and sorted into meaning units chiefly pertaining to the phenomenon of support in its absence and in its presence. The meaning of support seemed to be dissolved in the lived experience of being a family carer; therefore, in many cases, the narrative categories were short and scattered. Positive feelings of support were exemplified mainly in narratives of experienced drawn from within the AHCs. The narratives from family carers on being supported were strongly influenced by the significance of being, or rather becoming, affiliated with an AHC team, unlike the experience from some encounters they had had with health care outside of the AHCs, prior to becoming affiliated with an AHC team.

Meaning units from the narrative categories was gradually condensed according to the following sequential order. Meaning units were transformed into one or two sentences, condensed as closely to the initial text as possible. Meaning units and transformation were then taken into account when subthemes and themes were formulated. The choice of words in these formulations should represent an abstracted and deeper level of understanding without losing sight of the meaning of the text, that is, the utterance meaning (Ricoeur, 1976), by obfuscating formulations. Thus, 
TABLE 1: One Example of How Meaning Units Were Gradually Condensed

\begin{tabular}{|c|c|c|c|}
\hline Meaning Unit & Condensation & Subtheme & Theme \\
\hline $\begin{array}{l}\text { "but it has become a tremendous } \\
\text { relief with kind off inside of me } \\
\text { I can say, on account of the } \\
\text { AHC }{ }^{a} \text { being called in, because } \\
\text { then I don't feel that I have the } \\
\text { responsibility for his well-being } \\
\text { regarding the disease, but it's } \\
\text { they who take care of that. I } \\
\text { don't have to decide whether, } \\
\text { eeeh whether, there should be } \\
\text { more efforts put in and such, } \\
\text { instead they do that and I think } \\
\text { that feels really good. For me it } \\
\text { has been a tremendous relief." }\end{array}$ & $\begin{array}{l}\text { It feels good to be with } \\
\text { the AHC in caregiving } \\
\text { because they relieve } \\
\text { me of the responsibil- } \\
\text { ity of decisions. }\end{array}$ & $\begin{array}{l}\text { Being exempted } \\
\text { from } \\
\text { responsibility }\end{array}$ & $\begin{array}{l}\text { Experiencing a } \\
\text { togetherness with } \\
\text { others in caring }\end{array}$ \\
\hline
\end{tabular}

the formulations are not necessarily identical with the participants' choice of words. One example of this is displayed in Table 1.

When formulating the themes, we took time to dwell on the subthemes, condensation, and meaning unit, asking, What are these subtheme stories about (cf. Dostal, 1994)? In this phase of the analysis, we formulated two themes illuminating the meaning of support: Experiencing a togetherness with others in caring and Sensing togetherness with oneself in caring. We then revisited the material to make sure that the themes could be traced backward down to the initial text. Quotes from interviews are given below to illuminate the two themes. The quotes should be seen as examples rather than representatives for all subthemes. However, all subthemes have been capitalized in the text below.

\section{Experiencing Togetherness With Others in Caring}

The meaning of support was interpreted as Experiencing togetherness with others in caring. In the stories in which this meaning of support was present, family carers spoke about buoyancy in caring. They could sense themselves Feeling encircled by action potential. This sensing of a network that would step in, should they need it, was a great asset to them in the reassurance of honoring the promise that many had made to care for their relative at home until the end. Family carers spoke about a sense of entrustment that was established with their children but also with the AHC personnel. Family carers were assured that these could step in and take over caring, should the need arise. Simply knowing that they could confidently call their children or the AHC if anything should happen, was enough for most of the family carers. They spoke about a sense of trust in knowing where and whom to call and that the person they called would come through for them. One family carer narrated,

The AHC you can't, you can't praise them too much, because that they are something completely fantastic. I know one time when they had been here, he, what was it now? Yes, they had been here one evening and then it probably didn't take more 
than an hour before I had to call for them again and they came instantaneously and they came at night and they came in the morning and ... yes they are terrific.... I eeeh ... think, that kind of, if you have it so that you can call such wonderful people, then you needn't have such very, very big troubles. So I think we feel pretty good, I think ... and they say every time they're here that: "If it is anything then just call, because we are available around the clock," so eeeh . . . we think that's terrific actually.

The family carers spoke of a shared responsibility in caring in the possibility of Being exempted from responsibility at short notice or at particular moments. The family carers rested assured that they could and would get help or more help should they need it. They were no longer the sole accountable bearer of the wellbeing of their relative or for making decisions pertaining to the health of the person cared for. The immediate response of professionals, children, or friends when in need, or them calling and checking to see how the family carer was doing, was interpreted as a feeling of Being a priority to others. The subtheme Being seen and/or being heard was also elucidated in the stories. This was conveyed in stories in which the family carers felt they really had been listened to, when somebody had witnessed and recognized their situation as it was and showed an understanding. An example of this was when a health care professional had acknowledged the family carer's values, feelings, or struggles. Furthermore, when a health care professional paid attention to, noticed, or respected not only the relative but also the family carer, a feeling of Being paid deference to was expressed in the narratives.

The meaning of support interpreted as Experiencing togetherness with others in caring was dialectically displayed in family carers' narratives, in situations when experience of support was present or absent, respectively. Examples of negative feelings of support were mainly exemplified in narratives of experienced drawn prior to becoming affiliated with an AHC. In narratives elucidating the meaning of nonsupport, family carers spoke of a feeling of being overwhelmed by responsibility, experiencing insecurity, and aloneness. Family carers told about the difficult time after their loved one had been discharged from the hospital. Family carers spoke about Being forsaken, left to fend for themselves. They felt they had nowhere to turn to for help and that nobody cared about what happened with their family. Family carers tried to find pathways to call on professional help, but it seemed as if no one wanted to assume responsibility for making sure that service provision to the family or medical attention for the person being cared for was appropriate. One family carer narrated,

Because this was unbelievably tough, this was probably the toughest time when nobody listens, they listen to you and say certainly, right, sure we will do that, and then nothing happens. I think that is really bad because you should keep your promises ... You called: "No it's not our pigeon"; "No, it's not us"; "No, we have to have a referral from the physician" ... so that it was, $\mathrm{mmm}$, yeah five, six places before we got hold of someone who could help.

Family carers spoke about this as Being unable to attract attention to their situation. Often, the family ended up going to the emergency room at a hospital but still having the feeling of being disregarded or overlooked. The family carers spoke about having to pursue access to service assertively, expressing difficulties in attracting enough attention to rectify any situation at hand. The family carers wanted to help their loved one but were sometimes unable to do so without the aid 
of health care professionals. When family carers experienced being passed through the hands of all the relevant authorities without an appropriate response to resolve any issue at hand, they spoke about Being met with thoughtlessness, without deference. They experienced problems in finding someone who would help them take on the challenges that arose in caregiving, instead of offering temporary solutions or having a nonchalant attitude. At the same time, family carers struggled with Being anxious about deciding on future actions. Determining whether it was appropriate to seek professional help, for example if the condition of person they cared for worsened, could be difficult for family carers. They felt they had assumed the responsibility for the well-being of their relative. This was, for most, a 24-hour-a-day job. Also, Being powerless as a bystander feeling insufficient was difficult for the family carer. It was hard for them to witness the suffering of their family member without being able to do something. This was a perplexing feeling, wherein the family carers sometimes were in dire need of advice. Family carers spoke about Feeling irreplaceable and that, ultimately, it was they who were responsible for standing by their loved one. The feeling of Being alone with responsibility in caring for their charge could be more or less tangible for the family carers. The feeling was never completely erased, even if the family was affiliated with an AHC.

Several of the family carers were also parents of adult children. However, the family carers exerted themselves not to be a burden for their children; rather, they were Striving to remain emancipated from their children. The family carers were particular about letting their children lead their own lives, minding their jobs and families. Some family carers spoke about a similar aloneness or rather a sense of Being abandoned by their friends, as they had a tendency to pull away from the family. Then again, other family carers were Striving to balance attention from others with personal integrity, if friends were too eager to call wanting to know how the family was doing. This attention was not always perceived as positive by the family carers. Some family carers were well aware of the work that they did for their loved one, yet they felt Being disregarded, overlooked, or unappreciated by government authorities or the person for whom they cared. These family carers spoke about a feeling of lack of reciprocity in the work that they did and the value or respect others attached to it.

In narratives of service provision, the family carers spoke about Being unsatisfied while feeling the need to be grateful. This was exemplified in stories in which the family carer spoke about when services that they in some cases paid for did not meet their expectations, but still they did not want to complain. It could be that the cleaning service was slovenly or that the integrity of the home was not respected by professionals. The homey atmosphere was in jeopardy as the pursuit of making the home disability or worker friendly progressed.

Family carers' narratives also elucidated a feeling of Being joined together in enduring hardship. These stories illuminated the meaning of support that family carers found in sharing the emotional adversity with the person cared for, comforting each other in the presence of the challenge they both were facing.

\section{Sensing Togetherness With Oneself in Caring}

Several family carers' narratives illuminated the meaning of support as a sense of an inner quality in themselves. They spoke about having the ability to withstand the 
challenges of caring. Some perceived themselves as durable and capable of lasting. This was interpreted as Being persistently unyielding. As the family carers were faced with the challenges of caregiving, some found a unique unplumbed resourcefulness within themselves. One family carer narrated,

But it . . . as I say, it has been tough many times. You have to be strong. . . . I don't know if it is something inside you that does, that does that you, you have strengths that you didn't know about, that there is more to take out, although you feel sometimes that you are completely finished.

Although caregiving was challenging, family carers kept on caring, and some perceived themselves as having no choice but to continue. They stood fast to continue in spite of difficulties relying in their inner strength and keeping a positive attitude but surprised at the capacity that resided within them.

Diversion or distraction from the caregiving situation at hand also created a sense of a helpful or relaxing bubble of respite for the family carers. For a while, the diversion took their minds off of things. This could be exemplified in stories where the family carer had experienced respite care for both longer and shorter periods. Diversion was also found in day-to-day events, such as taking the dog for a walk in the forest or solving a crossword puzzle. For a moment, the family carer experienced Being distracted and pausing the endurance of hardship, only to resume shortly caring for their family member. One family carer said, "It's so good to have nature around you out here, $\mathrm{mmm}$... because then you can go out in the forest and find yourself again. " Another family carer narrated,

Yes, I take a magazine and do some crosswords and I am very often out with [name of the dog], take a long stroll with him in the afternoon when we have eaten dinner. Then I go out in the morning, go out in the forest with him, so that.

\section{SENSING TOGETHERNESS: THE INTERPRETED WHOLE AND REFLECTIONS}

The meaning of support was explained as consisting of the following themes: Experiencing a togetherness with others in caring and Sensing togetherness with oneself in caring. These themes pointed out the meaning of support, toward what is understood here as Sensing togetherness.

Although the family carers' narratives to some extent breathe a sense of fulfillment and joy of doing something good for a loved one, participants worry a great deal about the near future, and there is also much despair. This is illuminated in particular in incidents in which the family carer was at a loss as to what to do. From Wiles's (2003), study we recognize that family carers might feel confused about which services are available and from which institutions or agencies. This heavily constrains family carers' ability to access publicly funded support. Not knowing what to do and feeling abandoned or alone with caregiving could be labeled as feeling unsupported, for although the family carers are in need of support, they are also expected, sometimes by others but also by themselves, to support the person they care for. The family carers had assumed a responsibility that is a deeply human experience. This is a responsibility that they cannot waive. Lévinas (1990) wrote, 
I who support the other am responsible for him... I cannot waive my responsibility, no one could take my place ... the responsibility falls solely on me and I, cannot humanly, refuse to take it upon myself. . . . I can step into in everyone's place but no one can step into mine. (p. 117; authors' translation)

This responsibility cannot, and perhaps should not, be erased (Wiles, 2003). It is in preventing this responsibility from becoming overpowering that the idea of support is introduced. From the family carers' narratives on the meaning of support, we have learned that what family carers are in search of is someone to share this responsibility with, or, as formulated in Chambers, Ryan, and Connors (2001), to have someone at the end of the telephone-a lifeline. However, based on the family carers' narratives in our study, it has become clear that for the meaning of support as Sensing togetherness to be present, this person cannot be just anyone. It should be someone that the family carers feel they can trust. The dimension of shared responsibility for family carers and the understanding of the meaning of support as Sensing togetherness might be deepened by the writings of Aristotle (1967) on the idea of friendship, as it might illuminate the quality of the togetherness between the family carer and a potential supporter. Aristotle distinguished between different kinds of friendship, and the case in point here might be what is called a conditional friendship. Such a friend is not endeared for who he is but for his or her favors. Friendship presupposes togetherness, and within all forms of human togetherness there seem to be a kind of friendship (Aristotle, 1967). As elucidated by Aristotle, there is a quality of justice and morality that conditions the sense of togetherness or friendship that the family carers' narratives illuminated. This condition seems to revolve around a sense of security and certainty of assertive action. Our understanding is that to feel supported in a sense of togetherness in caregiving, the family carer must feel able to depend or rely on the supporter regardless of whether he or she is a trained professional. The idea of friendship in relation to support for family carers illuminates a dimension, which, to the best of our knowledge, has not yet been put forward within this research area. From this finding, we suggest that parallel to variations of different forms or ways to support family carers, there might exist a dimension of depth or level of engagement in the way in which the support is provided. This level of engagement can be understood in a broader sense through the idea of friendship. The concept of boundaries of friendship is mirrored by Aristotle's exposition of goodwill, which is the beginning of friendship but not identical with it. Persons who have goodwill toward you only wish you well, but you are hardly a participant in their endeavors or go to any lengths on their behalf. Instead, what is characteristic of a friend is that he or she benefits others, in particular if they are in need of it but did not ask for it themselves (Aristotle, 1967). To offer aid and assistance might be of particular importance, as family carers of senior persons might experience difficulties in asking for help themselves (Wiles, 2003). What has been disclosed by the above text was in the naive understanding's first level of interpretation formulated as to be sensing a genuine affinity with others; that people, through their way of being, speaking, and doing things, show that they really care for the family carer and their loved one equally.

In the findings from this study, the meaning of support is understood as Sensing togetherness. In another study within palliative home care, Milberg and Strang (2004) explored the concepts of comprehensibility and manageability in Antonovsky's (1987/1991) theory on sense of coherence by interviewing family 
carers. In their interpretation, Milberg and Strang found that the deeper meaning of manageability, on a more abstract level, concerned feelings of togetherness, as opposed to isolation, and that the core aspect of togetherness or isolation concerned a trust in surrounding resources and a shared responsibility. The togetherness made the family carers feel that they were not alone in fighting or managing the situation (Milberg \& Strang, 2004). The findings from the present study, as well as the results from Milberg and Strang, directed our attention toward Antonovsky's theory on sense of coherence as a theoretical base to further illuminate the meaning of support, in particular as regards the concept of manageability within the sense of coherence theory. A theoretical framework for understanding relatives' involvement in the care of the terminally ill has been developed by Andershed and Ternestedt $(1999,2001)$. In their model, Andershed and Ternestedt built on Antonovsky's sense of coherence theory and also stated that relatives' sense of coherence can be strengthened through adequate support.

By way of the idea of friendship, we have previously illuminated the importance of potential supporters' way of acting toward the family carers, as it has bearing on the sense of togetherness in caring. Andershed and Ternestedt (2001) further emphasized the importance health care professionals' humanistic attitude in their demeanor toward families, as this seem to influence relatives' ability to be involved in a meaningful way, along with a strong sense of coherence. At the highest level of meaningful involvement, the triad of the staff, relative, and patient is able to form a partnership in caring. However, a meaningful involvement can be undermined by a lack of commitment from staff, which we previously contrasted by the idea of goodwill. Andershed and Ternestedt went so far as to compare a lack of commitment to the opposite of care. The bearing on the meaning of support by surrounding persons' levels of engagement in family carers' challenges was described in the naive understanding's first level of interpretation as follows: feeling abandoned and disappointed, and feeling let down in the sense that no one recognized their needs. In such cases family carers spoke of being alone, that their suffering of themselves, or the suffering of the person they care for, was taken lightly or not acknowledged at all.

The meaning of support seems to be illuminated when the family carers tells about being in relation with others as well as being in relation with themselves in the challenge of giving care. The meaning of support, understood as Sensing togetherness, also seems to disclose a dimension of a resourcefulness residing within. This was illuminated by the family carers' narratives. Such narratives involved family carers' stories elucidating a sense of an inner unique resourcefulness or stories involving pets, nature, or in other ways "taking the mind off things" for a while. Dingley and Roux (2003) have studied the phenomenon of inner strength. By way of their formulations of the dimensions to inner strength, the meaning of support seems to verge on the phenomenon of inner strength or an inner capacity. For example, Dingley and Roux have formulated one dimension as "being supported by others" (p. 14), which resembles what has been discussed previously in this study. Another formulation of dimension is "drawing strength from the past" (p. 14). This later formulation might further broaden the understanding of the meaning of support, as it mirrors what is pointed out in narratives in which family carers spoke of the union with their loved one in enduring the challenge they both are facing, building on and drawing from the history they have together. Narratives about sensing an affinity with nature or with animals, or simply distracting the mind for a while, 
might correspondingly be mirrored in the dimension of Nurturing the spirit, which might open up for the phenomenon of inner strength to illuminate one aspect of the meaning of support.

Understanding the meaning of support as sensing togetherness, explained by the theme Sensing togetherness with oneself in caring, might be understood further when opened up to the phenomenon of inner strength or the capability of enduring difficult conditions, that is, hardiness (cf. Allen, 1990). The meaning of support seems to gravitate toward Sensing togetherness, which can be illuminated further by the concepts of friendship and inner strength.

In returning to Milberg and Strang (2004), we can see that the aspects of the meaning of support that have been illuminated in this study by the concepts of friendship and inner strength can be unified as a whole in the sense of togetherness. A feeling of togetherness involves trust in others or in oneself that there will be enough resources if something happens (Milberg \& Strang, 2004). We arrive at the conclusion that family carers' experience of a sense of togetherness seems to illuminate one meaning of support.

\section{SUGGESTIONS FOR FUTURE RESEARCH AND IMPLICATIONS FOR PRACTICE}

One important aspect of support for family carers that has been highlighted by this research is the value of the quality of interactions between family carers and health care professionals, illuminated by concepts such as friendship or humanistic attitude. Although the nature and quality of interactions between family and paid carers has increasingly been recognized, relationships largely remain overlooked, and few have examined the dynamics between the parties involved (Nolan, Grant, et al., 2003). In addition, health care professionals in general, and nurses in particular, are playing and will continue to play an important role in the cooperation between formal and informal caregiving in people's homes, as the home increasingly becomes the arena of caring for seniors. Therefore, a suggestion for future research might be to investigate further the relationship between family carers and nurses in terms of support. Such research might help to expand knowledge on support for family carers, which might contribute to excellence in nursing practice development.

The knowledge produced by this present study can be used by nurses as well as all health care professionals for critical reflection on the way in which they view support for family carers who care for a senior person at home. The knowledge and critical reflection might influence the way in which these health care professionals act in their encounter with family carers, thus potentially drawing on action-sensitive knowledge from this study (cf. van Manen, 1990). An important and possible implication for practice concerns family carers' having a sense of togetherness in caregiving (cf. Milberg \& Strang, 2004), a sense of togetherness to which there is a quality or level of engagement that can be accentuated by the idea of friendship, inner strength, or manageability from a sense of coherence point of view. What family carers seem to be seeking in terms of support from professionals, as well as from family and friends, is the establishment of a feeling of a reliable and dependable relation, perhaps, in other words, a partnership in caregiving (cf. Nolan, Lundh, 
Grant, \& Keady, 2003), so that they can experience the feeling of resources being readily available by which they can manage caregiving (cf. Antonovsky, 1987/ 1991).

\section{Methodological Considerations}

Earlier studies have shown that family carers who care for a senior person at home can experience their situation as stressful and worrisome (Stoltz et al., 2004). Therefore, we were attentive to the notion that participating in this study could be perceived as burdensome, time consuming, or even upsetting. Consequently, the ethical aspects of this study were given careful consideration, specifically in terms of the way in which family carers were approached. For example, the inquiries to participate were delivered by nurses working within the AHCs, as opposed to running the risk of family carers' feeling uncomfortable by being contacted directly by the authors, with whom they were unfamiliar. We did not want to handle any lists of names on family carers to minimize the risk of compromising confidentiality. These considerations resulted in a complicated but, we hope, nonintrusive recruitment process, with the main disadvantage being that we had no conception of the family carers who did not choose to participate. On the other hand, we are in accordance with Hutchinson, Wilson, and Skodol Wilson (1994) and S. Williams (1993), in that the family carers who did participate mainly felt good about sharing their experiences with the researchers, so that the experiences, in turn, might be disseminated to increase awareness. This was clearly stated to the interviewer (P.S.) by some family carers.

In this article, we chose to use the terminology of Lincoln and Guba (1985) to discuss further the trustworthiness of the study, although it can be criticized for being inconsistent with the philosophical underpinnings of qualitative research (Tobin \& Begley, 2004). The unacceptable alternative would be an outright rejection of the terms validity and reliability, which might ultimately result in qualitative research being rejected as a science (Morse, 1999).

The structural analysis in the phenomenological hermeneutical method (Lindseth \& Norberg, 2004) can be seen as an integrated process of verification (cf. Tobin \& Begley, 2004), which should decrease the risk of serious threats to reliability and validity, thus covering several aspects of trustworthiness (cf. Lincoln \& Guba, 1985) as well as reflexivity (cf. Malterud, 2001). By way of the structural analyses, the formulation of themes and subthemes can be traced back to the original interview transcripts. The interpretation of the meaning of a text is similar to a guess, according to Ricoeur (1976), and although there are no rules for making good guesses, there are rules for validating the guesses that we do make (Ricoeur, 1976). It is in this validation that the structural analyses play an important role in decreasing the risk of the "guess" being an entire figment of the researcher's imagination. In the interpreted whole, the findings are discussed in relation to other texts and results, not as a means of confirming existing data but as a means of enlarging the landscape of, in this case, the meaning of support, thus offering a deeper and more comprehensive picture (cf. Tobin \& Begley, 2004). The data were not coanalyzed; instead, all authors worked together throughout the research process to strengthen the research design, not by achieving consensus or arriving at identical formulations in 
interpretations but by supplementing and contesting each other's readings as a part of reflexivity (Malterud, 2001).

The present study can be criticized for its poor transferability to areas other than palliative care, where family care of senior persons is paramount, for example in caring for persons with dementia. However, the aim of this study was not to draw general conclusions about support for family carers. Instead, we used the present context of palliative care as an example and source of rich descriptions, which illuminated one meaning of support as it revealed itself through family carers' lived experiences of feeling supported or feeling unsupported. We welcome similar studies in other areas or settings, as they might contribute to enlarge or enrich the description of the phenomenon of support.

The first author's (P.S.) inexperience as an interviewer might be a limitation to the study, as this might have influenced the success in retrieving exhaustive narratives from interviewees. For example, the family carers' narratives about support might be viewed as short and scattered, as previously stated. On the other hand, what is said during the interviews might be viewed as a wish to be understood as a whole person, whereby narratives on support were interwoven with the experience of being a family carer, even though the researcher asked about a specific aspect of family caring, namely, support. Therefore the meaning of support seemed to be dissolved in the lived experience of being a family carer. However, even if the interviewer had been more experienced, we do not believe the interviews to have turned out completely different, as an interview also is a joint construction between interviewer and interviewee (cf. Mishler, 1986).

The result of this study is only one interpretation of several possible, and no single interpretation will ever exhaust the possibility of a richer or deeper understanding (van Manen, 1990). Other or additional choices of literature might illuminate different aspects of the meaning of support in the interpreted whole. Then again, a highly abstract interpretation might be at risk of rendering the result meaningless, if the interpretation becomes too all encompassing.

\section{REFERENCES}

Allen, R. E. (Ed.). (1990). The concise Oxford dictionary of current English. Oxford, UK: Clarendon. Andershed, B., \& Ternestedt, B. M. (1999). Involvement of relatives in the care of the dying in different care cultures: Development of a theoretical understanding. Nursing Science Quarterly, 12(1), 45-51.

Andershed, B., \& Ternestedt, B. M. (2001). Development of a theoretical framework describing relatives' involvement in palliative care. Journal of Advanced Nursing, 34(4), 554-562.

Andersson, M. (1996). Integritet som begrepp och princip —En studie av ett vårdetiskt ideal i utveckling [Integrity as a concept and principle-A study of a caring ethics ideal in development]. Unpublished doctoral dissertation, Åbo Akademis förlag, Åbo, Sweden.

Antonovsky, A. (1991). Hälsans mysterium [Unraveling the mystery of health] (M. Elfstadius, Trans.). Stockholm, Sweden: Natur och Kultur. (Swedish translation of original work published in 1987)

Aristotle. (1967). Den nikomachiska etiken [The Nicomachian ethics] (M. Ringbom, Trans.). Göteborg, Sweden: Daidalos.

Beck-Friis, B., \& Strang, P. (Eds.). (1995). Palliativ medicin [Palliative medicine]. Stockholm, Sweden: Liber. Beeson, R. A. (2003). Loneliness and depression in spousal caregivers of those with Alzheimer's disease versus non-caregiving spouses. Archives of Psychiatric Nursing, 17(3), 135-143.

Borglin, G., Edberg, A.-K., \& Rahm Hallberg, I. (2005). The experience of quality of life among older people. Journal of Aging Studies, 19(2), 201-221. 
Chambers, M., Ryan, A. A., \& Connor, S. L. (2001). Exploring the emotional support needs and coping strategies of family carers. Journal of Psychiatric and Mental Health Nursing, 8(2), 99-106.

Chang, B. L., Nitta, S., Carter, P. A., \& Markham, Y. K. (2004). Perceived helpfulness of telephone calls: Providing support for caregivers of family members with dementia. Journal of Gerontological Nursing, 30(9), 14-21.

Cooke, D. D., McNally, L., Mulligan, K. T., Harrison, M. J. G., \& Newman, S. P. (2001). Psychosocial interventions for caregivers of people with dementia: A systematic review. Aging Mental Health, 5(2),120135 .

Covinsky, K. E., Newcomer, R., Fox, P., Wood, J., Sands, L., Dane, K., et al. (2003). Patient and caregiver characteristics associated with depression in caregivers of patients with dementia. Journal of General Internal Medicine, 18, 1006-1014.

Dingley, C., \& Roux, G. (2003). Inner strength in older Hispanic women with chronic illness. Journal of Cultural Diversity, 10(1), 11-22.

Dostal, R. (1994). The experience of truth for Gadamer and Heidegger: Taking time and sudden lightning. In B. Wachterhauser (Ed.), Hermeneutics and truth (pp. 47-67). Evanston, IL: Northwestern University Press.

Dröes, R. M., Breebaart, E., Meiland, F. J., van Tilburg, W., \& Mellenbergh, G. J. (2004). Effect of meeting centres support program on feelings of competence of family carers and delay of institutionalization of people with dementia. Aging Mental Health, 8(3), 201-211.

Gilliland, M., \& Bush, H. A. (2001). Social support for family caregivers: Toward a situation-specific theory. Journal of Theory Construction and Testing, 5(2), 53-62.

Glueckauf, R. L., Ketterson, T. U., Loomis, J. S., \& Dages, P. (2004). Online support and education for dementia caregivers: Overview, utilization, and initial program evaluation. Telemedicine Journal and E-Health, 10(2), 223-232.

Harding, R., \& Higginson, I. J. (2003). What is the best way to help caregivers in cancer and palliative care?: A systematic literature review of interventions and their effectiveness. Palliative Medicine, 17(1), 63-74.

Harding, R., Higginson, I. J., Leam, C., Donaldson, N., Pearce, A., George, R., et al. (2004). Evaluation of a short-term group intervention for informal carers of patients attending a home palliative care service. Journal of Pain Symptom Management, 27(5), 396-408.

Hellström, Y., \& Rahm Hallberg, I. (2004). Determinants and characteristics of help provision for elderly people living at home and in relation to quality of life. Scandinavian Journal of Caring Sciences, 18(4), 387-395.

Hirschman, K. B., Shea, J. A., Xie, S. X., \& Karlawish, J. H. T. (2004). The development of a rapid screen for caregiver burden. Journal of the American Geriatrics Society, 52(10), 1724-1729.

Hutchinson, S. A., Wilson, M. E., \& Skodol Wilson, H. (1994). Benefits of participating in research interviews. Image: The Journal of Nursing Scholarship, 26(2), 161-164.

Kristjanson, L. J., Cousins, K., White, K., Andrews, L., Lewin, G., Tinnelly, C., et al. (2004). Evaluation of a night respite community palliative care service. International Journal of Palliative Nursing, 10(2), 8490.

Lévinas, E. (1990). Etik och oündlighet [Ethics and infinity] (M. G. Contassot, Trans.). Stockholm, Sweden: Symposion.

Lincoln, Y. S., \& Guba, E. G. (1985). Naturalistic inquiry. London: Sage.

Lincoln, N. B., Walker, M. F., Dixon, A., \& Knights, P. (2004). Evaluation of a multiprofessional community stroke team: A randomized controlled trial. Clinical Rehabilitation, 18(1), 40-47.

Lindseth, A., \& Norberg, A. (2004). A phenomenological hermeneutical method for researching lived experience. Scandinavian Journal of Caring Sciences, 18(2), 145-153.

Malterud, K. (2001). Qualitative research: Standards, challenges, and guidelines. The Lancet, 358, 483-488.

Milberg, A., \& Strang, P. (2004). Exploring comprehensibility and manageability in palliative home care: An interview study of dying cancer patients' informal carers. Psycho-oncology, 13(9), 605-618.

Mishler, E. (1986). Research interviewing: Context and narrative. London: Harvard University Press.

Morse, J. M. (1999). Myth 93: Reliability and validity are not relevant to qualitative inquiry. Qualitative Health Research, 9, 717-718.

Neufeld, A., \& Harrison, M. J. (2003). Unfulfilled expectations and negative interactions: Nonsupport in the relationships women caregivers. Journal of Advanced Nursing, 41(4), 323-331.

Nolan, M., Grant, G., \& Keady, J. (1996). Understanding family care: A multidimensional model of coping and caring. Buckingham, UK: Open University Press. 
Nolan, M., Lundh, U., Grant, G., \& Keady, J. (Eds.). (2003). Partnerships in family care: Understanding the caregiving career. Maidenhead, UK: Open University Press.

Pusey, H., \& Richards, D. (2001). A systematic review of the effectiveness of psychosocial interventions for carers of people with dementia. Aging Mental Health, 5(2),107-119.

Richards, K., Moniz-Cook, E., Duggan, P., Carr, I., \& Wang, M. (2003). Defining "early dementia" and monitoring intervention: What measures are useful in family caregiving? Aging Mental Health, 7(1), 7-14.

Ricoeur, P. (1976). Interpretation theory: Discourse and the surplus of meaning. Fort Worth: Texas Christian University Press.

Ricoeur, P. (1981). Hermeneutics and the human sciences (J. B. Thompson, Ed.). Cambridge, UK: Cambridge University Press.

Ricoeur, P. (1991). From text to action: Essays in hermeneutics (Vol. 2). Evanston, IL: Northwestern University Press.

Rollison, B., \& Carlsson, M. (2002). Evaluation of advanced home care (AHC): The next-of-kin's experiences. European Journal of Oncology Nursing, 6(2), 100-106.

Sands, L. P., Ferreira, P., Stewart, A. L., Brod, M., \& Yaffe, K. (2004). What explains differences between dementia patients' and their caregivers' ratings of patients' quality of life? American Journal of Geriatric Psychiatry, 12(3), 272-280.

SBU (Swedish Council of Technology Assessment in Healthcare). (1999). Avancerad hemsjukvård och hemrehabilitering [Advanced home care and home rehabilitation]. Stockholm, Sweden: Author.

SCB Statistiska centralbyrån (Statistics Sweden). (2003). The density of the population in Sweden. Retrieved January 12, 2005, from http:/ / www.scb.se/

Socialtjänstlag (2001:453) [The Swedish social services act (2001:453)]. Retrieved January 12, 2005, from http://rixlex.riksdagen.se

Stoltz, P., Udén, G., \& Willman, A. (2004). Support for family carers who care for an elderly person at home: A systematic literature review. Scandinavian Journal of Caring Sciences, 18(2), 111-119.

Strandberg, G., Norberg, A., \& Jansson, L. (2000). An exemplar of a positive perspective of being dependent on care. Scholarly Inquiry for Nursing Practice, 14(4), 327-346.

Sundström, G., Johansson, L., \& Hassing, L. B. (2002). The shifting balance of long-term care in Sweden. The Gerontologist, 42(3), 350-355.

Tobin, G. A., \& Begley, C. M. (2004). Methodological rigour within a qualitative framework. Journal of Advanced Nursing, 48(4), 388-396.

van Manen, M. (1990). Researching lived experience: Human science for an action sensitive pedagogy. London, Ontario, Canada: SUNY.

Wiles, J. (2003). Informal caregivers' experiences of formal support in a changing context. Health and Social Care in the Community, 11(3), 189-207.

Williams, P., Barclay, L., \& Schmied, V. (2004). Defining social support in context: A necessary step in improving research, intervention, and practice. Qualitative Health Research, 14, 942-960.

Williams, S. G. (1993). How do the elderly and their families feel about research participation? Geriatric Nursing, 14(1), 11-14.

World Health Organization. (2003). WHO Definition of palliative care. Retrieved November 14, 2005, from http://www.who.int/cancer/palliative/definition/en/

Peter Stoltz, RN, BNSc, is a doctoral student in the School of Health and Society, Malmö University, Malmö, Sweden.

Ania Willman, RN, BEd, PhD, is a senior lecturer in the School of Health and Society, Malmö University, Malmö, Sweden.

Giggi Udén, RNM, PhD, is a professor in the School of Health and Society, Malmö University, Malmö, Sweden. 